\title{
Electrochemical synthesis and optical properties of ultra-fine CdSe nanoparticles
}

\author{
S. S. Fomanyuk ${ }^{1}$ - V. N. Asaula ${ }^{1}$ - G. Ya Kolbasov ${ }^{1}$ - T. A. Mirnaya ${ }^{1}$
}

Received: 9 June 2016/Accepted: 29 July 2016/Published online: 6 August 2016

(c) The Author(s) 2016. This article is published with open access at Springerlink.com

\begin{abstract}
Colloidal solutions $(\sim 0.3 \mathrm{~mol} / \mathrm{L})$ of $\mathrm{CdSe}$ nanoparticles in xylene have been synthesized by the electrochemical method from an acid electrolyte based on $\mathrm{HNO}_{3}+\mathrm{HCl}(2: 1)$ mixture using extraction into xylene. It has been found that CdSe nanoparticles of small size $(2-5 \mathrm{~nm})$ synthesized on the cathode are readily extractable in xylene, whereas nanoparticles of larger size $(20-100 \mathrm{~nm})$ remain in the aqueous electrolyte and dissolve in the nitric-hydrochloric acids mixture. An X-ray phase analysis of powders of 2-5 nm CdSe nanoparticles showed them have a mixed cubic/hexagonal crystal structure. It has been found from measurements of absorption and photoluminescence spectra that the CdSe nanoparticles of this structure have a broad photoluminescence band $\left(\lambda_{\max }=500 \mathrm{~nm}\right)$ at a narrow absorption peak $\left(\lambda_{\max }=420 \mathrm{~nm}\right)$, which may be due to stacking fault formation in nanoparticles of mixed cubic/hexagonal structure. Using this electrolyte with a xylene surface layer under continuous electrolysis conditions and extraction of 2-5 nm CdSe nanoparticles with a content of up to $0.05 \mathrm{~g}$ in $1 \mathrm{~cm}^{3}$ xylene $(\sim 0.3 \mathrm{~mol} / \mathrm{L})$ was obtained. Such colloidal solution can be used to obtain optical nanocomposites by incorporation CdSe nanoparticles into a liquidcrystalline cadmium caprylate matrix. The spectral characteristics such of composites have been studied by adsorption spectroscopy and fluorescence.
\end{abstract}

S. S. Fomanyuk

fomanyuk@gmail.com

1 V.I. Vernadskii Institute of General and Inorganic Chemistry of Ukrainian NAS, Prospekt Palladina 32-34, Kiev 03142, Ukraine
Keywords CdSe nanoparticles · Electrosynthesis . Extraction $\cdot$ Liquid-crystalline matrix

\section{Background}

The interest in semiconductor nanoparticles of metal chalcogenides is due to the pronounced difference of their optical properties from the properties of bulk material, i.e., to the dependence of their absorption and luminescence spectra on size. CdSe nanocrystals based on its nano heterostructures are promising as materials for optical and optoelectronic devices [1,2], solar batteries $[3,4]$, fluorescent labels in biophysical processes [5, 6]. CdSe nanocrystals are prepared in most cases by chemical methods of template synthesis or controlled precipitation in solution using surfactants as stabilizators [5]. However, such synthesis methods not always allow one to achieve a high nanoparticles concentration, which is often required in the creation of thin-film optical composites. To attain this aim, joint synthesis of nanoparticles and their matrix or modification of grown nanoparticles with surfactant molecules for compatibility with their matrix is used $[7,8]$.

Purification of nanoparticles by centrifugation (purification-dissolution method) [9] is also widely used in the fabrication of nanocomposite materials, but this method is technologically complex and labor intensive [10]. Since small CdSe nanoparticles are known to be able to be quickly extracted in water-immiscible organic solvents [11], we proposed a method for the preparation of CdSe nanocrystals by electrosynthesis from aqueous solutions with their simultaneous extraction into xylene. Empirically, we have found that along with the formation of large CdSe cathode deposits $(20-150 \mathrm{~nm})$ a 
colloidal solution of CdSe nanoparticles $(2-5 \mathrm{~nm})$ is also formed during dc electrolysis. Our studies of the effect of the electrolyte composition on the concentration of ultrafine CdSe nanoparticles showed that under constant electrolysis conditions, the formation of such nanoparticles is accompanied by the formation of larger amounts of large (20-150 nm) nanocrystals. The reaction yield of large nanoparticles was ten times higher than that for small nanoparticles extracted into xylene. For example, during electrosynthesis in an electrolyte based on sulfuric acid, the amount of $\mathrm{CdSe}$ nanoparticles extracted into xylene was no more than $3 \mathrm{~mol} \%$, while the rest of CdSe deposited on the cathode as deposits with large nanoparticles $(20-100 \mathrm{~nm})$. Because the concentration of starting reactants (selenious acid and cadmium sulfate) decreases during electrolysis, the quantity of small $(2-10 \mathrm{~nm})$ nanoparticles extracted from the solution decreases too. It is known that CdSe crystals dissolve quickly in a $\mathrm{HNO}_{3}+\mathrm{HCl}$ mixture to form starting reagents $\mathrm{CdCl}_{2}$ and $\mathrm{H}_{2} \mathrm{SeO}_{3}$ [12]. Thus, the electrosynthesis of $\mathrm{CdSe}$ in electrolytes based on a nitric acidhydrochloric acid mixture with simultaneous extraction of ultrafine nanoparticles into xylene may be a promising way of preparing concentrated colloidal solutions of such nanoparticles since the amount of extracted small nanoparticles increases by factor of ten compared to using electrolyte based on the sulfuric acid. The colloidal solutions obtained with high percentage of ultrafine $\mathrm{CdSe}$ nanoparticles in xylene were used for incorporation into a liquid-crystalline matrix. As known the liquid-crystalline melts of metal alkanoates such as cadmium caprylate can be supercooled that leads to the subsequent formation of an anisotropic glass at the room temperature [13]. By melting and subsequently cooling a mixture of cadmium caprylate with CdSe nanoparticles, an optically transparent glassy material has been obtained. It is a new perspective material for many applications including laser and sensors of near-ultraviolet and blue visible spectral range. It has been found that the thermo-optical nonlinearity of cadmium caprylate composites containing $\mathrm{CdSe}$ nanocrystals are characterized by extremely large value of the nonlinear refractive index under relatively low-powered $\mathrm{CW}$ laser irradiation [14]. Large optical nonlinearity parameters and fast response times, together with the excellent photoand thermo-stability of nanocomposites make them extremely promising for optical processing applications. The aim of this research was to create optical glassy composites with CdSe nanoparticles, which are prepared by the electrosynthesis of colloidal solutions with high percentage of ultrafine $(2-5 \mathrm{~nm})$ CdSe nanoparticles in xylene and are incorporated into a liquid-crystalline cadmium caprylate matrix.

\section{Experimental method}

The electrosynthesis of CdSe nanoparticles was carried out from acid solutions of analytically pure $\mathrm{CdCl}_{2}$ and $\mathrm{H}_{2} \mathrm{SeO}_{3}$ in two-electrode mode using a graphite anode and a titanium cathode. The cathode current density of electrosynthesis $\left(\sim 200 \mathrm{~mA} / \mathrm{cm}^{2}\right)$ was controlled with an EP-21 potentiostat, the temperature $\left(95^{\circ} \mathrm{C}\right)$ was maintained with a U1 thermostat. To extract simultaneously $\mathrm{CdSe}$ nanoparticles during electrosynthesis, the cell was filled with xylene (Labscan) to $1 / 4$ of the electrolyte volume (Fig. 1). To prepare a concentrated colloidal solution of CdSe nanoparticles in xylene $(0.3 \mathrm{~mol} / \mathrm{L}), 5$-h continuous electrolysis of an electrolyte $\left(2.26 \mathrm{~mol} / \mathrm{L} \mathrm{HNO}_{3}, 1 \mathrm{~mol} /\right.$ $\mathrm{L} \mathrm{HCl}, 0.081 \mathrm{~mol} / \mathrm{L} \mathrm{H}_{2} \mathrm{SeO}_{3}$ and $0.084 \mathrm{~mol} / \mathrm{L} \mathrm{CdCl}_{2}$ ) with $200 \mathrm{~mA} / \mathrm{cm}^{2}$ current at $95{ }^{\circ} \mathrm{C}$ was used. The concentration of nanoparticles was determined by gravimetric method from the dry residue of evaporated colloidal solutions of $\mathrm{CdSe}$ nanoparticles and after annealing at $500^{\circ}$.

The resulting colloidal solution was mixed with thermotropic liquid crystal of cadmium caprylate and heated at $150{ }^{\circ} \mathrm{C}$. The boiling temperature of xylene $\left(138^{\circ} \mathrm{C}\right)$ is within the temperature range of the mesophase existence of cadmium caprylate $\left(98-165^{\circ} \mathrm{C}\right)$ [15]. Due to the evaporation of xylene, the $\mathrm{CdSe}$ nanoparticles were uniformly distributed throughout the volume of the mesophase of cadmium caprylate, and on cooling this melt, a glassy nanocomposite was formed. The structure of CdSe powders has been investigated by $\mathrm{X}$-ray phase analysis on a DRON-4 diffractometer, using $\mathrm{CuK} \alpha$ radiation (wavelength $1.5418 \AA$ A). $2 \theta$ measuring range: $10^{\circ}-70^{\circ}$ with a step of 0.1 . The powder has been obtained by the evaporation of a colloidal solution of CdSe nanoparticles in xylene at $150{ }^{\circ} \mathrm{C}$. Morphology of the nanocomposites has been studied by transmission electron microscopy (TEM) with a JEM 100 CX2 operating at $100 \mathrm{kV}$. Powder of cadmium caprilate containing $\mathrm{CdSe}$ nanoparticles has been dissolved

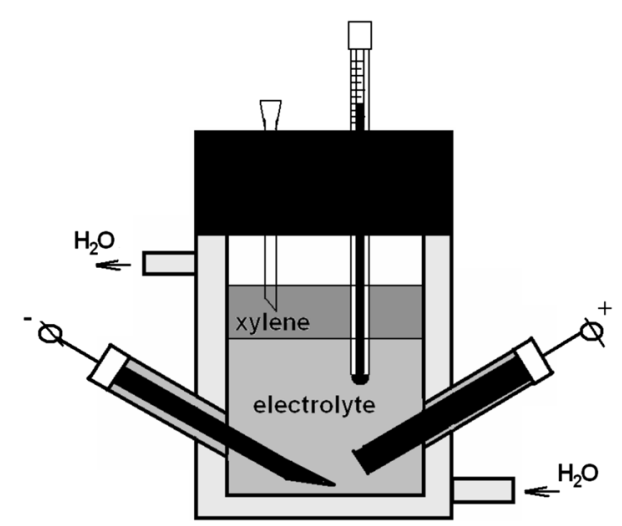

Fig. 1 Cell for the electrosynthesis of CdSe nanoparticles and simultaneous extraction in xylene 
in toluene which dissolved the matrix partially. Then drop of solution was dried in air on copper-carbon mesh.

IR spectra were recorded on a Specord M80 IR Spectrophotometer using $\mathrm{KBr}$ pellets. The optical absorption and photoluminescence of CdSe nanoparticles in xylene and glassy mesophase of cadmium caprylate were studied on Perkin Elmer UV-Vis Lambda 35 and Perkin Elmer LS 55 spectrophotometers.

\section{Results and discussion}

Electrochemical investigations of an electrolyte based on a $\mathrm{HNO}_{3}+\mathrm{HCl}$ mixture showed this electrolyte to have promise in the preparation of colloidal solutions of small $(2-5 \mathrm{~nm})$ CdSe nanoparticles. Using this electrolyte with a surface layer of xylene under continuous electrolysis conditions, one can obtain extracts of CdSe nanoparticles with a content of $0.3 \mathrm{~mol} / \mathrm{L}$ in xylene. The same colloidal solutions were used to fabricate optical nanocomposites based on thermotropic liquid-crystalline matrix. During electrosynthesis without the use of anticoagulating agents, CdSe nanoparticles as powder or dendrite-like deposits are formed on the cathode. The presence of water-immiscible xylene and vigorous hydrogen evolution result in the formation of an electrolyte-xylene emulsion in the cathode layer. In the layer of this emulsion, the synthesis and simultaneous extraction of CdSe nanoparticles take place. Being extracted into xylene, they do not yield anymore to action of the acid medium in the electrolyte. Since xylene is a nonpolar solvent, and coagulate very little, if at all. For small nanoparticles, xylene is stabilizing additive, whereas larger nanoparticles precipitate within some time after extraction. This may be due to interaction between the $\pi$ bonds of xylene molecules and CdSe nanoparticles [16]. Owing to this interaction, small nanoparticles do not yield to the action of gravitational force and do not precipitate, whereas for larger nanoparticles, the interaction with the $\pi$ bonds of xylene molecules is insufficient to retain them. The authors of Refs [17, 18] argue that the adsorption activity of nanoparticles against hydrocarbon molecules depends on their size and surface state. The surface activity of small nanoparticles is higher at small volume and mass; they interact with organic solvent molecules better than larger nanoparticles [17, 18].

Since selenious acid is used as selenium source in the formation of $\mathrm{CdSe}$, it is expedient to find in what form selenious acid is in the solution based on the $\mathrm{HNO}_{3}-\mathrm{HCl}$ mixture ( $\mathrm{pH} \approx 1.5$ ). Selenious acid is known to change its ionic form depending on solution $\mathrm{pH}$. Figure 2 shows plots of the distribution of ionic forms of $\mathrm{H}_{2} \mathrm{SeO}_{3}$ against $\mathrm{pH}$, which were calculated by the procedure presented in [19] for the first and second dissociation constants of selenious

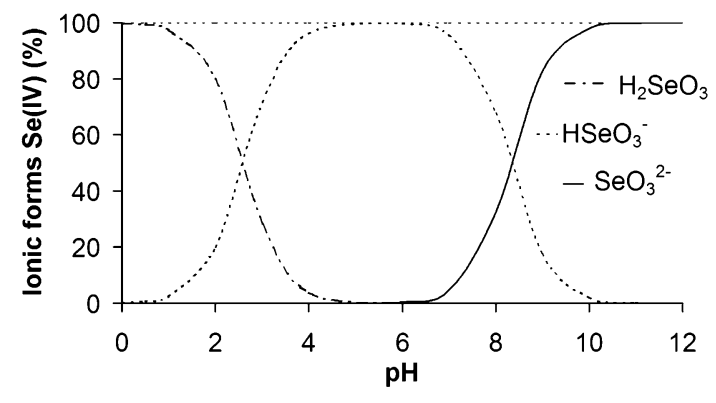

Fig. 2 Diagram of distribution of ionic forms $\mathrm{H}_{2} \mathrm{SeO}_{3}$ as a function of $\mathrm{pH}$

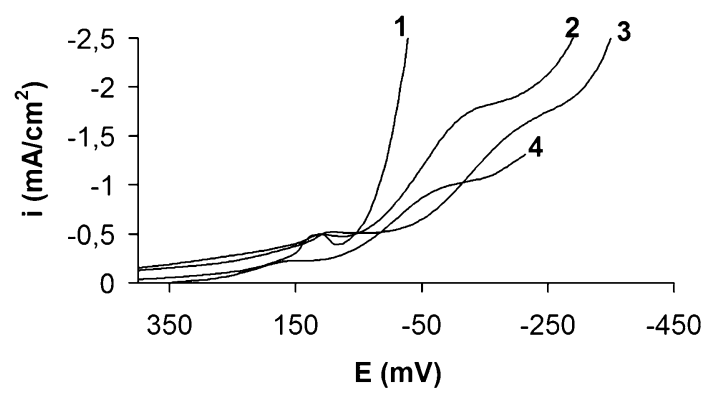

Fig. 3 Polarization curves at a temperature of $95{ }^{\circ} \mathrm{C}$ for solutions: $\mathrm{HNO}_{3}(2.26 \mathrm{~mol} / \mathrm{L})+\mathrm{HCl}(1 \mathrm{~mol} / \mathrm{L})$ supporting electrolyte (1); supporting electrolyte and $\mathrm{H}_{2} \mathrm{SeO}_{3}(0.081 \mathrm{ml} / \mathrm{L})$ (2); supporting electrolyte, $\mathrm{H}_{2} \mathrm{SeO}_{3}(0.081 \mathrm{ml} / \mathrm{L})$ and $\mathrm{CdCl}_{2}(0.084 \mathrm{~mol} / \mathrm{L})$ (3); supporting electrolyte and $\mathrm{CdCl}_{2}(0.084 \mathrm{~mol} / \mathrm{L})(4)$

acid. Increase in $\mathrm{pH}$ value and $\mathrm{H}_{2} \mathrm{SeO}_{3}$ concentration increases its ability for dissociation into ions. As it is seen from the diagram in Fig. 2, in acid electrolyte based on a $\mathrm{HNO}_{3}+\mathrm{HCl}(2: 1)$ mixture, molecule does not almost dissociate at $\mathrm{pH} \approx 1,5$.

Voltammetric investigations of the CdSe formation process showed (Fig. 3) that the curves 2 and 4 of cadmium and selenium formation in supporting electrolyte based on a $\mathrm{HNO}_{3}+\mathrm{HCl}$ mixture are at close potential values. The shift of the curve 2 in Fig. 3 towards more negative values relative to the curve 1 , which is responsible for hydrogen evolution from the supporting electrolyte, indicates inhibition of the hydrogen evolution reaction on the reduction of selenious acid. Since the shift of the curve 4 in Fig. 3 towards more negative values relative to the curve 1 for the process of electroreduction of $\mathrm{Cd}^{2+}$ ions is still larger than for the formation process (curve 3 in Fig. 3), we assume that the synthesis of CdSe in this supporting electrolyte may take place by an electrochemical-chemical mechanism.

In this acid electrolyte $(\mathrm{pH}=1.5)$ the formation process of CdSe nanoparticles in an acid medium can be described by the following reactions [20]:

$$
\begin{aligned}
& \mathrm{H}_{2} \mathrm{SeO}_{3}+4 \mathrm{H}^{+}+6 \mathrm{e}=\mathrm{Se}^{2-}+3 \mathrm{H}_{2} \mathrm{O}, \\
& \mathrm{Cd}^{2+}+\mathrm{Se}^{2-}=\text { CdSe. }
\end{aligned}
$$


Increasing the electrolysis temperature contributes to the rapid grown of small CdSe nanoparticles. Studies of the effect of temperature on electrochemical processes of $\mathrm{CdSe}$ (Fig. 4a) showed that an increase in current wave with increase in temperature gradient up to $95^{\circ} \mathrm{C}$ is observed, i.e., temperature rise leads to an increase in the rate of CdSe formation.

Figure $4 \mathrm{~b}$ shows the dependence of the logarithm of current on reciprocal temperature $(1 / T)$. The activation energy of the $\mathrm{CdSe}$ nanoparticles electrosynthesis process has been determined to be $35 \mathrm{~kJ} / \mathrm{mol}$. The activation energy of $\mathrm{CdSe}$ nanoparticles formation in electrochemical synthesis coincides with that in high-temperature chemical growth in paraffin acid-oleic acid mixture [21]. Since the activation energy of the electrosynthesis and chemical growth of $\mathrm{CdSe}$ nanoparticles is the same $(\approx 35 \mathrm{~kJ} / \mathrm{mol})$ [21], it may be assumed that the rate-determining step of the formation of $\mathrm{CdSe}$ nanoparticles is the diffusion of the original reactants $\mathrm{H}_{2} \mathrm{SeO}_{3}$ and $\mathrm{Cd}^{2+}$ to the cathode according to Eqs. (1) and (2). We have estimated the diffusion coefficient using cyclic voltammetry and the Randles-Sevcic equation.

The cyclic voltammograms for different potential scan in Fig. 5a showed that the electrochemical stage of CdSe formation from this electrolyte is irreversible. As be seen, the curves in Fig. 5a at different potential scan rate have only one peak in the case of direct polarization. In the case of reverse polarization, the dissolution peak of the electrolysis products formed on the cathode is absent. This indicates that either the electrolysis products dissolve chemically or are removed mechanically from the electrode surface. The aforesaid polarization studies showed that in our case, both the former and latter take place.

Based on Fig. 5b it is safe to say, for the linear dependence of the current maximum $i_{p}$ on the square root of potential scan rate $v^{0.5}$, that there are diffusion limitations for the electrochemical stage of the process (Eq. 1) [22]. To describe the effect of potential scan rate on the current density peak $i_{p}$ of current-potential curve, we use the Randles-Sevcik equation [22]:

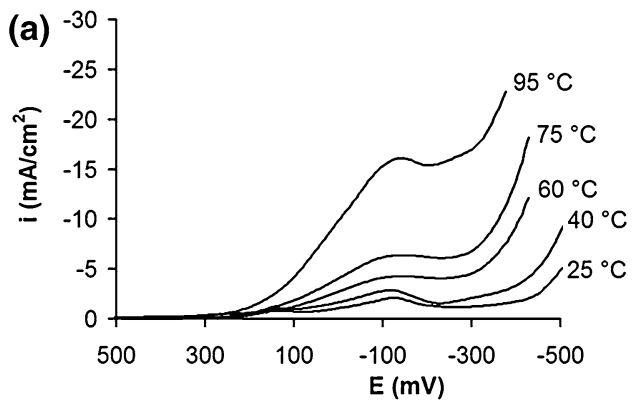

Fig. 4 Polarization curves of CdSe formation from an electrolyte of the composition: $2.26 \mathrm{~mol} / \mathrm{L} \mathrm{HNO}_{3}, 1 \mathrm{~mol} / \mathrm{L} \mathrm{HCl}, 0.081 \mathrm{~mol} / \mathrm{L} \mathrm{H}_{2-}$ $\mathrm{SeO}_{3}$ and $0.084 \mathrm{~mol} / \mathrm{L} \mathrm{CdCl}_{2}$ at different temperatures (a); $i_{p}=0.4463 n F A C(n F v D / R T)^{0.5}$,

where $i_{p}$ current maximum in amp, $n$ number of electrons transferred in the redox event (usually 1), $A=$ electrode area in $\mathrm{cm}^{2}, F$ Faraday Constant in $\mathrm{C} \mathrm{mol}^{-1}, D$ diffusion coefficient in $\mathrm{cm}^{2} / \mathrm{s}, C$ concentration in $\mathrm{mol} / \mathrm{cm}^{3}, v$ scan rate in $\mathrm{V} / \mathrm{s}, R$ universal gas constant.

Using this equation, one can determine the diffusion coefficient $D$ of selenious acid molecules. From the reactions 1 and 2 it is evident that the electrochemical stage of $\mathrm{CdSe}$ formation takes place through the reduction of selenious acid to $\mathrm{Se}^{2-}$; it follows that by substituting the Faraday constant, the concentration of $\mathrm{H}_{2} \mathrm{SeO}_{3}$ molecules $\left(c=8.4 \times 10^{-5} \mathrm{~mol} / \mathrm{cm}^{3}\right)$ for the 6-electron $\mathrm{Se}^{2-}$ formation reaction 1 and the slope of the straight line in Fig. $5 \mathrm{~b}$ into Eq. (3), the diffusion coefficient can be found to be $2.1 \times 10^{-7} \mathrm{~cm}^{2} / \mathrm{s}$. A comparison of diffusion coefficients of $\mathrm{H}_{2} \mathrm{SeO}_{3}\left(D \approx 5.75 \times 10^{-6} \mathrm{~cm}^{2} / \mathrm{s}\right)$ in CdSe formation [23] with our value $D \approx 2.1 \times 10^{-7} \mathrm{~cm}^{2} / \mathrm{s}$ showed that in our case, the presence of nitric acid increases by an order of magnitude the diffusion limitations of CdSe electroformation.

It was found that $\mathrm{CdSe}$ nanoparticles powder is characterized by the hexagonal cubic mixed crystal modification using X-ray powder analysis [24]. Figure 6a shows X-ray diffraction (XRD) pattern for two crystal CdSe modifications. The amorphous XRD pattern exhibits characteristic peaks centered at $2 \theta$ values $23.5^{\circ}, 56^{\circ}$ and which are correspond to hexagonal (wurtzite) and cubic modifications, respectively. The large broadening of the peaks may be the result of the merging of the peaks of two crystalline modifications. According to the Scherrer formula, the broadening of the peaks can be up to $10^{\circ}$ and more at the size of nanoparticles of $2-5 \mathrm{~nm}$. Accordingly, several peaks may merge to form broad peaks. The proof of this is an XRD diffractogram of CdSe after annealing at $500{ }^{\circ} \mathrm{C}$ (Fig. 6b). In this figure, the peaks of $\mathrm{CdSe}$ of cubic and hexagonal modification can be clearly seen. In further optical studies it was established that the size of nanoparticles is $2-5 \mathrm{~nm}$.

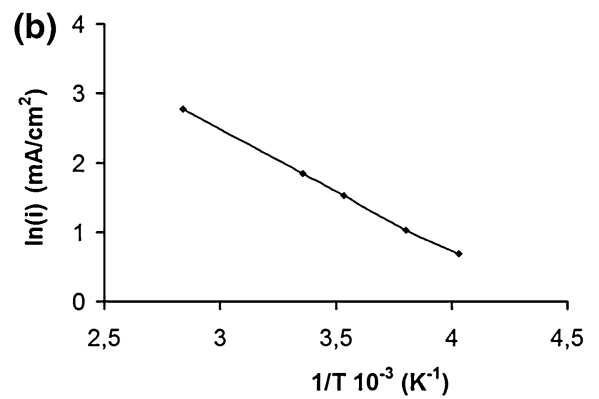

dependence of the logarithm of current on reciprocal temperature for the process of CdSe nanoparticles formation on a titanium cathode $(E=-105 \mathrm{mV})(\mathbf{b})$ 


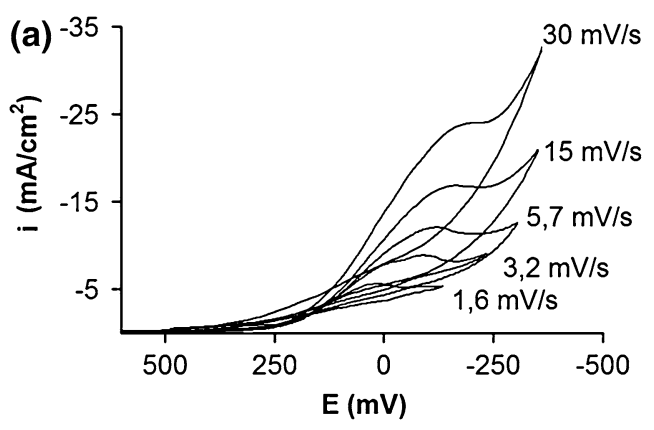

Fig. 5 Cyclic voltammograms of CdSe electrosynthesis from an electrolyte of the composition: $2.26 \mathrm{~mol} / \mathrm{L} \mathrm{HNO}_{3}, 1 \mathrm{~mol} / \mathrm{L} \mathrm{HCl}$, $0.081 \mathrm{~mol} / \mathrm{L} \mathrm{H}_{2} \mathrm{SeO}_{3}$ and $0.084 \mathrm{~mol} / \mathrm{L} \mathrm{CdCl}_{2}$ at $95{ }^{\circ} \mathrm{C}$ (a);

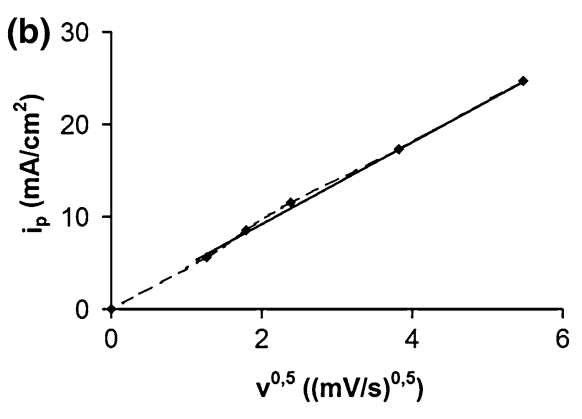

dependence of current on the square root of potential scan rate for the process of $\mathrm{CdSe}$ nanoparticles formation on a titanium cathode (b)
Fig. 6 XRD diffractograms of powder of CdSe nanoparticles obtained by drying a xylenebased colloidal solution (a) and after annealing at $500{ }^{\circ} \mathrm{C}(\mathbf{b})$ (a)
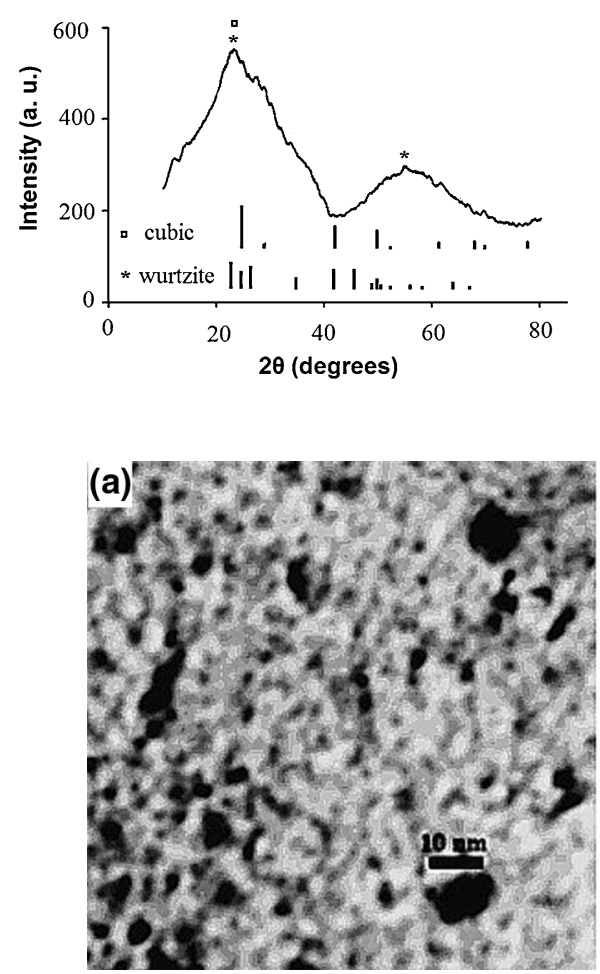
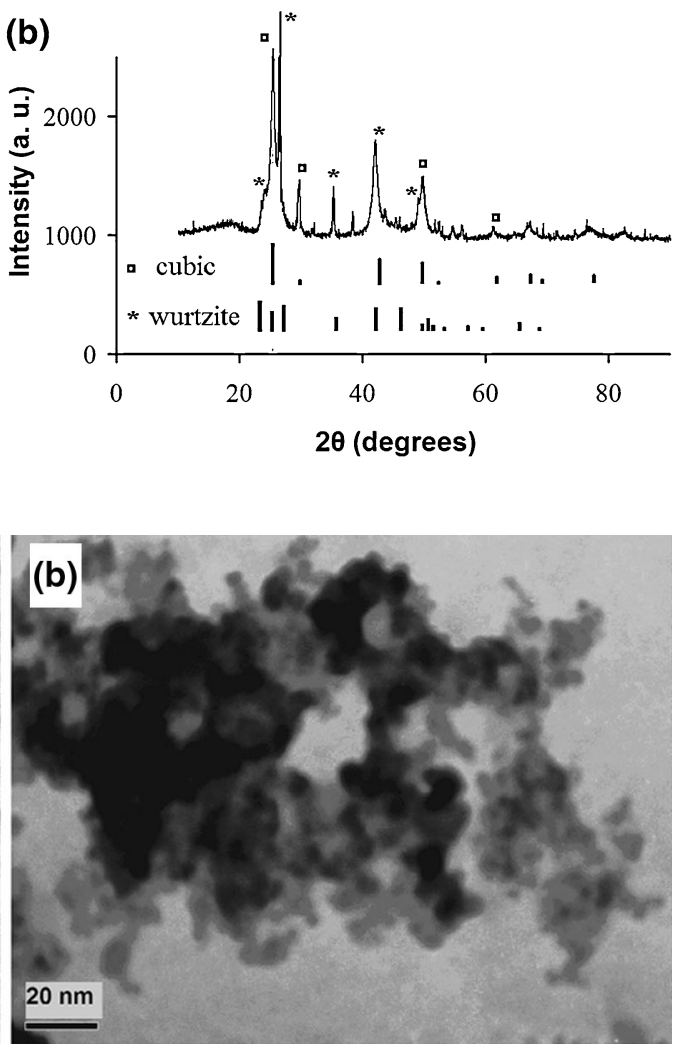

Fig. 7 TEM image of the CdSe nanoparticles in cadmium caprylate matrix (a) and of powder of CdSe nanoparticles (b)
The colloidal solution of CdSe nanoparticles in xylene was mixed with thermotropic liquid crystal of cadmium caprylate at $150{ }^{\circ} \mathrm{C}$. When all xylene was evaporated a liquid crystalline melt was cooled, and a glassy nanocomposite with $\mathrm{CdSe}$ nanoparticles was formed. The TEM picture of CdSe nanoparticles shows the nanoparticles with dimensions from 2 to $10 \mathrm{~nm}$ (Fig. 7a), i.e., these particles coagulate not strongly in cadmium caprylate since it dissolves partially in xylene and forms, as a surfactant, a micellar solution with cadmium selenide nanoparticles, hindering thereby their coagulation.

The nanoparticles without cadmium caprylate matrix coagulate to form agglomerates of up to $20 \mathrm{~nm}$ size
(Fig. 7b). Figure 7b shows that the agglomerates consist mainly of small nanoparticles of up to $5 \mathrm{~nm}$ size.

It is known that a mixed crystal structure is typical of small CdSe nanoparticles [25]. Investigations of the optical properties of nanoparticles with mixed structure showed them to have narrow absorption peaks mainly at 350-450 nm and broad photoluminescence bands with maximum at $\sim 500-550 \mathrm{~nm}$ [25]. Figure 8 shows absorption and emission spectra of CdSe nanoparticles $(\sim 2 \mathrm{~nm})$ dissolved in xylene. It can be seen that they absorb light at $420 \mathrm{~nm}$ and emit bright green luminescence with maximum at $500 \mathrm{~nm}$. When investigating the photoluminescence properties of small $(2-5 \mathrm{~nm})$ nanoparticles, the 


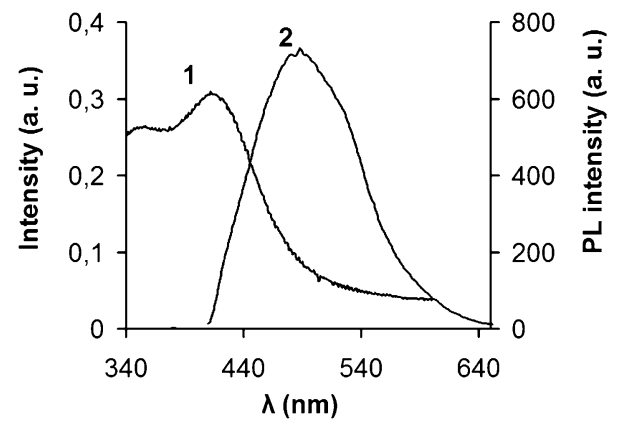

Fig. 8 Optical absorption (1) and photoluminescence (2) spectra of a colloidal solution $\left(\sim 10^{-2} \mathrm{~mol} / \mathrm{L}\right)$ of CdSe nanoparticles in xylene. The photoluminescence excitation wavelength is $400 \mathrm{~nm}$

authors of the paper [26] found that when their structure changes from cubic to mixed cubic/hexagonal one, the luminescence peak broadens and shifts to the longer-wave region. These optical properties are attributed to stacking fault formation in nanoparticles of mixed cubic/hexagonal structure [25].

A nanocomposite based on a liquid-crystalline cadmium caprylate matrix and CdSe particles was investigated by the methods of absorption spectroscopy and luminescence. Figure 9 shows absorption and photoluminescence spectra of thin (1-2 mm) films of liquid-crystalline cadmium caprylate composite with 6 mol. \% CdSe between two quartz glass plates. The films absorb light heavily in the UV region (300-400 $\mathrm{nm}$ ) and exhibit photoluminescence properties in the visible region $(450-550 \mathrm{~nm})$.

As in the case (Fig. 8, curve 2), the emission spectrum has a broad band at $\lambda=500 \mathrm{~nm}$, i.e., relates to the socalled green luminescence [27]. The large half-width of the peak is due to a set of nanoparticles in the range $2-5 \mathrm{~nm}$. The green emission maximum may also be assigned to the so-called impurity luminescence of interstitial selenium, i.e., to the recombination of donor level electrons with holes captured to the acceptor level [28].

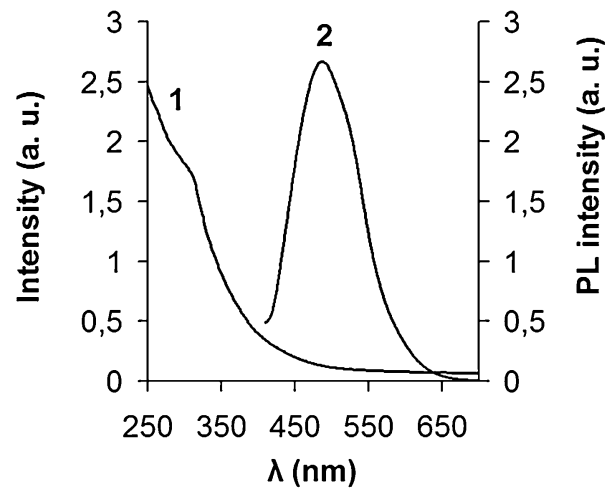

Fig. 9 Optical absorption (1) and photoluminescence (2) spectra of glassy mesophase of cadmium caprylate with $\mathrm{CdSe}$ nanoparticles (6 mol\%). The photoluminescence excitation wavelength is $400 \mathrm{~nm}$
In contrast to luminescence spectra, the absorption maximum of the liquid-crystalline nanocomposite (Fig. 9, curve 1) is shifted towards the UV light region. It is evidence about that the CdSe nanoparticles into xylene interact with the solvent forming of micellar structures from its molecules. It is provable by the infrared spectroscopy of CdSe powders obtained by evaporation of the colloidal solution of xylene.

An analysis of the chemical composition of powders of colloidal CdSe nanoparticles by IR spectroscopy (Fig. 10) showed the presence of vibrations at 612 and $410 \mathrm{~cm}^{-1}$, which corresponds to the $\mathrm{Cd}-\mathrm{Se}$ bond [29-31]. Besides the peaks at 612 and $410 \mathrm{~cm}^{-1}$, which are typical of $\mathrm{Cd}-\mathrm{Se}$ bond, there are a $\mathrm{C}-\mathrm{H}$ peak $\left(2920 \mathrm{~cm}^{-1}\right)$ and a $\mathrm{C}=\mathrm{C}$ peak $\left(1610 \mathrm{~cm}^{-1}\right)$ of the group $[32,33]$, indicating the adsorption of molecules of organic substances (xylene in our case) on the CdSe surface [29-31]. The peak at $1260 \mathrm{~cm}^{-1}$ is associated with the absorption of $\mathrm{C}=\mathrm{O}$ and $\mathrm{C}-\mathrm{C}-\mathrm{O}$ groups as remnants of molecules of oxidized xylene adsorbed on the surface of CdSe nanoparticles. The peaks at 2406 and $3450 \mathrm{~cm}^{-1}$ correspond to contribution to the absorption of $\mathrm{CO}_{2}$ and $\mathrm{H}_{2} \mathrm{O}$ molecules in air and as condensed moisture on the sample surface [29, 32]. High intensity of peaks which corresponded to $\mathrm{C}=\mathrm{O}$ and $\mathrm{C}-\mathrm{O}-\mathrm{H}$ characteristic groups of carboxylic acids confirms the formation of micellar structures of aromatic carboxylic acids on the surface of CdSe nanoparticles. Comparison of the two spectra of CdSe powder and $p$-toluic acid showed that on the surface of CdSe nanoparticles are adsorbed molecules of $p$-toluic acid. As can be seen from Fig. 10, the spectrum of CdSe nanoparticles (1) exhibits traces of the spectrum $p$-toluic acid (2). The vibrations of the aromatic $\mathrm{C}=\mathrm{C}$ group and $\mathrm{O}-\mathrm{H}$ carboxyl group are particularly intense (Fig. 10(1)).

According to [17] CdSe nanoparticles modified with benzoic acid interact with xylene (toluene) from causing a change of their optical properties. In our electrolyte, a strong oxidizing medium was created in which impurities

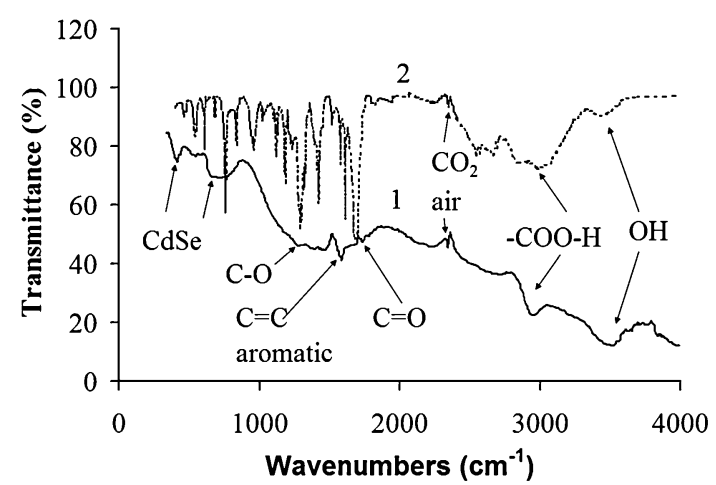

Fig. 10 IR spectrum of a CdSe powder obtained by drying a colloidal solution of $\mathrm{CdSe}$ nanoparticles in xylene at $300{ }^{\circ} \mathrm{C}(1)$ and $p$-toluic acid (2) 
of an aromatic carboxylic acid, isomers of the toluic acid [34] and its radicals (toluic aldehyde and xylene hydroperoxide) $[35,36]$ are formed due to the presence of hydrochloric and nitric acids and the temperature of $95^{\circ} \mathrm{C}$. Toluic acid as well as benzoic acid is a substance which interacts with the surface of the nanoparticles via the carboxyl groups to form micellar structures. At that benzene ring was obtained onto the micelle surface and interacts with xylene. Since toluic acid has limited solubility in water and high solubility in xylene then such micelle are retained in xylene easier than in aqueous media. Similar methods are used to extract silver nanoparticles into nonpolar organic solvents from aqueous phase [37]. Organic carboxylic acids or their salts are used as interfacial carriers and stabilizers simultaneously [38]. Thus, small nanoparticles with light weight easily adsorbed from the aqueous phase. The large ( $\approx 20-100 \mathrm{~nm}$ ) nanoparticles are formed on the cathode for a longer time and are weakly retained in xylene layer over the aqueous electrolyte surface and under the influence of gravitational forces pass over gradually back into the aqueous phase. It was noticed that after 15-min electrolysis with simultaneous extraction into xylene and separation of xylene from the aqueous solution with the acid of separating funnel, large CdSe nanoparticles settle as a red sediment.

We assume that the electrosynthesis of CdSe using an electrolyte with $\mathrm{pH}=1.5$ facilitates the formation of colloidal solutions of CdSe nanoparticles more than that of coarse cathode deposits. The ultrafine CdSe nanoparticles $(2-5 \mathrm{~nm})$ are quickly extracted by xylene; larger nanocrystals are dissolved by $\mathrm{HNO}_{3}+\mathrm{HCl}$ mixture. As a result of this dissolution at $95{ }^{\circ} \mathrm{C}$, reverse formation of $\mathrm{H}_{2} \mathrm{SeO}_{3}$ and $\mathrm{Cd}^{2+}$ ions takes place by the action of $\mathrm{HNO}_{3}$ [39] by the reactions:

$$
\begin{aligned}
& 3 \mathrm{CdSe}+8 \mathrm{HNO}_{3}= 3 \mathrm{Cd}\left(\mathrm{NO}_{3}\right)_{2}+3 \mathrm{Se}+2 \mathrm{NO} \\
&+4 \mathrm{H}_{2} \mathrm{O}, \\
& 3 \mathrm{Se}+4 \mathrm{HNO}_{3}+\mathrm{H}_{2} \mathrm{O}=3 \mathrm{H}_{2} \mathrm{SeO}_{3}+4 \mathrm{NO} .
\end{aligned}
$$

The small $(2-5 \mathrm{~nm})$ nanoparticles have no time to dissolve in acid electrolyte because they are quickly extracted into the water-immiscibe xylene layer, which hinders their contact with the acid medium. Therefore, the concentration of CdSe nanoparticles extracted into xylene increases greatly. For example, the concentration of the nanoparticles extracted from an electrolyte based on sulfuric acid does not exceed $0.03 \mathrm{~mol} / \mathrm{L}$, whereas the concentration of nanoparticles extracted from an electrolyte based on nitric acid-hydrochloric acid mixture is $0.3 \mathrm{~mol} / \mathrm{L}$ after 5 -h electrolysis in both cases. High optical absorption indexes (Fig. 10, curve 1) of liquid-crystalline nanocomposite thin films base on cadmium caprylate with $6 \mathrm{~mol} \% \mathrm{CdSe}$ nanoparticles $(2-5 \mathrm{~nm})$ also show that electrosynthesis is promising technique for producing a liquid-crystalline nanocomposite further. Investigations of similar liquidcrystalline nanocomposites films obtained by template synthesis [14] showed that in them due to the local heating control laser light the refractive index of the smectic liquid crystal are changed and the light output is redirected to another area. Since solely localized areas of contact with the laser radiation act in such films then the last may be effectively used as high-speed $(1.2 \mathrm{~ms})$ matrices for optical processing and transmission of optical signals.

\section{Conclusions}

It has been shown that colloidal solution of $\mathrm{CdSe}$ nanoparticles $(\approx 0.3 \mathrm{~mol} / \mathrm{L})$ in xylene can be obtained by electrosynthesis from an acid electrolyte based on a $\mathrm{HNO}_{3}+\mathrm{HCl}(2: 1)$ mixture using the method of extraction into xylene. It has been found that the formation of $\mathrm{CdSe}$ nanoparticles proceeds by a mixed electrochemicalchemical mechanism in an acid electrolyte based on an $\mathrm{HNO}_{3}+\mathrm{HCl}(2: 1)$ mixture. We assume that the small nanoparticles remain in the dissolved form owing to chemical interaction with xylene molecules, whereas the large nanoparticles settle by gravity. An analysis of IR spectra of powders of 2-5 nm CdSe nanoparticles from a dried colloidal solution (at $300{ }^{\circ} \mathrm{C}$ ) showed that besides the peaks at 612 and $410 \mathrm{~cm}^{-1}$ for the CdSe bonds, there are $\mathrm{C}-\mathrm{H}$ peaks $\left(2928 \mathrm{~cm}^{-1}\right)$ and peaks at $1260 \mathrm{~cm}^{-1} \mathrm{C}=\mathrm{O}$ and $\mathrm{C}-\mathrm{C}-\mathrm{O}$ groups indicating on the adsorption of xylene and oxidized xylene molecules on the CdSe surface. Due to the presence of these groups on the surface of CdSe nanoparticles, their extraction process may be performed by aromatic carboxylic acids toluic acid isomers. The carboxyl groups of these acids bind to the surface of the CdSe nanoparticles forming micellar structure, which promotes their dissolution in xylene.

An X-ray phase analysis of powders of $2-5 \mathrm{~nm} \mathrm{CdSe}$ nanoparticles showed them have a mixed cubic/hexagonal crystal structure. It has been found from measurements of absorption and photoluminescence spectra that the $\mathrm{CdSe}$ nanoparticles of this structure have a broad photoluminescence band $\left(\lambda_{\max }=500 \mathrm{~nm}\right)$ at a narrow absorption peak $\left(\lambda_{\max }=420 \mathrm{~nm}\right)$, which may be due to stacking fault formation in nanoparticles of mixed cubic/hexagonal structure. The incorporation of electrochemically synthesized CdSe nanoparticles into a mesophase of cadmium caprylate from a colloidal solution allows one to obtain an optical composite with high percentage $(6 \mathrm{~mol} \%)$ of ultrafine CdSe nanoparticles. Since solely localized areas of contact with the laser radiation act in such films then the last may be effectively 
used as high-speed (1.2 ms) matrices for optical processing and transmission of optical signals.

Open Access This article is distributed under the terms of the Creative Commons Attribution 4.0 International License (http://creative commons.org/licenses/by/4.0/), which permits unrestricted use, distribution, and reproduction in any medium, provided you give appropriate credit to the original author(s) and the source, provide a link to the Creative Commons license, and indicate if changes were made.

\section{References}

1. Colvin, V.L., Schlamp, M.C., Alivisatos, A.P.: Light-emitting diodes made from cadmium selenide nanocrystals and a semiconducting polymer. Nature 370, 354-357 (1994)

2. Tsutsui, T.: Applied physics: a light-emitting sandwich filling. Nature 420, 752-755 (2002)

3. Xu, X., Giménez, S., Mora-Seró, I., Abate, A., Bisquert, J., Xu, G.: Influence of cysteine adsorption on the performance of CdSe quantum dots sensitized solar cells Mater. Chem. Phys. 124, 709-712 (2010)

4. Hossain, M.A., Yang, G., Parameswaran, M., Jennings, J.R., Wang, Q.: Cascade quantum dots sensitized $\mathrm{TiO}_{2}$ nanorod arrays for solar cell applications. Nanoscale 3, 4940-4942 (2011)

5. Trindade, T., O'Brien, P., Pickett, N.L.: Nanocrystalline semiconductors: synthesis, properties, and perspectives. Chem. Mater. 13, 3843-3858 (2001)

6. Medintz, I.L., Uyeda, H.T., Goldman, E.R., Mattoussi, H.: Quantum dot bioconjugates for imaging, labelling and sensing. Nat. Mater. 4, 435-446 (2005)

7. Pang, L., Tetz, K., Shen, Y., Chen, C.H., Fainman, Y.J.: Photosensitive quantum dot composites and their applications in optical structures. J. Vac. Sci. Technol. B 23, 2413-2419 (2005)

8. Tomczak, N., Janczeuski, D., Han, M., Vancson, G.J.: Designer polymer-quantum dot architectures. Prog. Polym. Sci. 34, 393-430 (2009)

9. Yaacob, K.A., Ishak, M.N., Alias, N.N.: Quantum dots sensitized solar cell: effect of CdSe nanoparticles purification procedure of QD sensitized photoanodes. J. Phys. Conf. Ser. 431, 012019-012028 (2013)

10. Bass, J.D., Ai, X., Bagabas, A., Rice, P.M., Topuria, T., Scott, J.C., Alharbi, F.H., Kim, H.-C., Song, Q., Miller, R.D.: An efficient and low-cost method for the purification of colloidal nanoparticles. Angew. Chem. Int. Ed. 50, 1-6 (2011)

11. Mu, J., Gao, X., Zhang, Y., Sun, H., Liu, L.: Photoluminescence properties of $\mathrm{CdSe}$ nanocrystals from water into organic phase using 1-dodecylmercaptan as phase transfer reagent. J. Dispers. Sci. Technol. 27, 77-81 (2006)

12. Tuck, B.: The chemical polishing of semiconductors. J. Mater. Sci. 10, 321-339 (1975)

13. Mirnaya, T.A., Volkov, S.V.: Ionic liquid crystals as universal matrices (solvents): main criteria for ionic mesogenicity. In: Rogers, R.D., Seddon, K.R., Volkov, S.V. (eds.) Green industrial applications of ionic liquids, pp. 439-456. Kluwer Academic Publishers, London (2002)

14. Lyashchova, A., Fedorenko, D., Garbovskiy, Yu., Klimusheva, G., Mirnaya, T., Asaula, V.: Strongthermal optical nonlinearity caused by CdSe nanoparticles synthesised in smectic ionic liquid crystal. Liq. Cryst. 40, 1377-1382 (2013)

15. Nordell, K.J., Boatman, E.M., Lisensky, G.C., Safer, A.: Easier, faster synthesis for CdSe quantum dot nanocrystals. J. Chem. Educ. 82, 1697-1699 (2005)
16. Hirosawa, Y., Kouzai, H., Miyagawa, H., Tsurumachi, N., Koshiba, S., Nakanishi, S., Biju, V., Ishikawa, M.: Dynamic Interactions of $\mathrm{CdSe} / \mathrm{ZnS}$ quantum dots with cyclic solvents probed by femtosecond four-wave mixing. EPJ Web Conf. 04036, 41 (2013)

17. Vassiltsova, O.V., Zhao, Z., Petrukhinaa, M.A., Carpenter, M.A.: Surface-functionalized CdSe quantum dots for the detection of hydrocarbons. Sens. Actuators B 123, 522-529 (2007)

18. Potyrailo, R.A., Leach, A.M.: Selective gas nanosensors with multisize CdSe nanocrystal/polymer composite films and dynamic pattern recognition. Appl. Phys. Lett. 88, 134110-134113 (2006)

19. Benedicto, A., Missana, T., Degueldre, C.: Predictions of $\mathrm{TiO}_{2--}$ driven migration of $\mathrm{Se}(\mathrm{IV})$ based on an integrated study of $\mathrm{TiO}_{2}$ colloid stability and Se(IV) surface adsorption. Sci. Total Environ. 449, 214-222 (2013)

20. Pawar, S.M., Moholkar, A.V., Bhosale, C.H.: Influence of pH on electrochemically deposited CdSe thin films. Mater. Lett. 61, 1034-1038 (2007)

21. Hamizi, N.A., Johan, M.R.: Enhanced ripening behaviour of cadmium selenide quantum dots (CdSe QDs). Int. J. Electrochem. Sci. 7, 8473-8480 (2012)

22. Zanello, P.: Inorganic electrochemistry: theory, practice and application. The Royal Society of Chemistry, Cambridge (2003)

23. Lukinskas, A., Savickaja, I., Jasulaitienè, V., Juodkazytè, J., Juodiene, T., Kalinauskas, P.: Regularities of electrochemical formation of thin CdSe films on Ti surface. Chemija (Vilnius) 13(2), 89-96 (2002)

24. Sapra, S., Rogach, A.L., Feldmann, J.: Phosphine-free synthesis of monodisperse CdSe nanocrystals in olive oil. J. Mater. Chem. 16(33), 3391-3395 (2006)

25. Chen, X., Hutchison, J.L., Dobson, P.J., Wakefield, G.: A onestep aqueous synthetic route to extremely small CdSe nanoparticles. J. Colloid. Interface Sci. 319, 140-143 (2008)

26. Farva, U., Park, C.: Influence of thermal annealing on the structural and optical properties of $\mathrm{CdSe}$ nanoparticles. Sol. Energy Mater. Sol. Cells 94, 303-309 (2010)

27. Singh, V., Chauhan, P.: Structural and optical characterization of CdS nanoparticles prepared by chemical precipitation method. J. Phys. Chem. Solid 70, 1074-1079 (2009)

28. Singh, V., Sharma, P.K., Chauhan, P.: Synthesis of CdS nanoparticles with enhanced optical properties. Mater. Charact. 62, 43-52 (2011)

29. Khanna, P.K.: Synthesis and Optical Properties of CdSe Nanocrystals: effective Use of Organoselenium Compound in Nanochemistry. Synth. React. Inorg. Met. Org. Nano Met. Chem. 38, 409-413 (2008)

30. Seoudi, R., Mongy, S.A.E., Shabaka, A.A.: Effect of polyvinyl alcohol matrices on the structural and spectroscopic studies of CdSe nanoparticles. Phys. B 403, 1781-1786 (2008)

31. Khudiar, A.I., Zulfequar, M., Khan, Z.H.: Influence of cadmium concentration on the optical and structural properties of cadmium selenide thin films. Mater. Sci. Sem. Proc. 15, 536-542 (2012)

32. Friedel, R.A., Carlson, G.L.: Difficult carbonaceous materials and their infrared and Raman spects, reassignments for coal spectra. Fuel 51, 194-198 (1972)

33. Shih, J.H., Osawa, Y., Fujii, S.: Infrared spectra of heat treated coal. Fuel 51, 153-155 (1972)

34. Rao, T.S.S., Shubhra, A.: Oxidation of alkylaromatics. E J. Chem. 4, 1-13 (2007)

35. Stephens, H.N., Roduta, F.L.: Oxidation in the benzene series by gaseous oxygen. V. The oxidation of tertiary hydrocarbons. J. Am. Chem. Soc. 57, 2380-2381 (1935)

36. Hartmann, M., Seiberth, M.: Über ein Tetralin-peroxyd. Helv. Chim. Acta 15, 1390-1392 (1932) 
37. Cheng, W., Dong, S., Wang, E.: Two- and three-dimensional au nanoparticle/CoTMPyP self-assembled nanotructured materials: film structure, tunable electrocatalytic activity, and plasmonic properties. J. Phys. Chem. B 108, 19146-19154 (2004)
38. Yang, Y., Liu, S., Kimura, K.: Cyclodextrin as a capturing agent for redundant surfactants on $\mathrm{Ag}$ nanoparticle surface in phase transfer process. Colloids Surf. A 290, 143-149 (2006)

39. Gopalan, R.: Inorganic chemistry for undergraduates. Universities Press, Hyderabad (2009) 